\title{
NORMAS DE RECONHECIMENTO DAS PESSOAS COM DEFICIENCIA: REFLEXÕES A LUZ DE RAWLS E HONNETH
}

\author{
Micaela Barros Barcelos Fernandes ${ }^{1}$
}

\begin{abstract}
Resumo
Tendo por suporte fático a mudança legislativa ocorrida no ordenamento brasileiro com relação às pessoas com deficiência, através da aprovação da Lei 13.146/2015, o objetivo deste trabalho é destacar a importância do estudo das teorias filosóficas que se ocupam do reconhecimento para a formação do pensamento crítico na criação e interpretação das normas jurídicas de inclusão. Foi utilizado o método descritivo para análise de textos de John Rawls e Axel Honneth, tomando-se alguns referenciais teóricos formulados pelos autores, notadamente sobre o tema da participação no contrato social (na obra de Rawls) e sobre a luta por reconhecimento (na obra de Honneth). Da leitura dos textos dos dois autores, conclui-se que ambos ajudaram a construir uma fundamentação filosófica para a necessidade da participação das pessoas com deficiência no processo legislativo e na formulação de políticas públicas para uma tutela mais efetiva de seus direitos. Apesar deste resultado, e dos avanços legislativos recentes, em considerações finais a autora pondera que ainda há muito a se caminhar para que se concretizem os ideais de inclusão traçados no ordenamento brasileiro em vigor.
\end{abstract}

Palavras-chave: Reconhecimento; Inclusão; Estatuto da Pessoa com Deficiência; John Rawls; Axel Honneth.

\section{INTRODUÇÃO}

O objetivo deste trabalho é contribuir para a reflexão sobre a importância do estudo de diferentes teorias filosóficas que se ocupam do reconhecimento como etapa fundamental na formação do pensamento crítico, e, sobretudo, da ação responsável por qualquer ator social na criação e interpretação das normas jurídicas de inclusão.

Foram escolhidas, como referência para o desenvolvimento do tema, as teorias de John Rawls e Axel Honneth. Ambos os autores podem contribuir para o melhor entendimento do processo de elaboração e aplicação da norma jurídica, que é meio de conformação de (determinado) contrato social, mas também de constituição do(s) indivíduo(s) a que se destina, ao reconhecer, ou não, direitos e acesso a direitos.

Foi utilizado o método descritivo para análise dos escritos de John Rawls e Axel Honneth, tomando-se alguns referenciais teóricos formulados pelos autores, notadamente sobre o tema da participação no contrato

${ }^{1}$ Doutoranda em Direito Civil (UERJ - ingresso em 2017.E-mail: mibbf@yahoo.com.br 
social como meio para escolha dos princípios de justiça aplicáveis a todos (na obra de Rawls) e sobre a luta por reconhecimento (na obra de Honneth).

O trabalho é dividido em quatro partes. Na primeira, é traçado muito sucintamente o percurso da relação da sociedade com as pessoas com deficiências, desde uma fase de exclusão, motivada por fundamentos morais e religiosos, passando pela segregação e pela integração, mais fundamentada em uma perspectiva restritamente médica das deficiências, até a fase de inclusão, em que se adota uma perspectiva muito mais abrangente, um olhar multidisciplinar para a questão da deficiência, identificada com o modelo social no seu tratamento.

$\mathrm{Na}$ segunda parte, já assumida a fase de inclusão na relação com a deficiência, em que se encontra a sociedade brasileira na atualidade, são apresentadas as mudanças legislativas recentes, desde a última década do século XX até o ano de 2016, quando aprovada a Lei 13.146, de 2015, conhecida como o Estatuto da Pessoa com Deficiência, que buscou tratar de maneira ampla as diversas questões relacionadas às pessoas com deficiência, tanto em seus aspectos existenciais quanto patrimoniais.

A partir da terceira parte, propõe-se uma reflexão filosófica sobre os avanços normativos obtidos, com base substancialmente nas obras de Rawls e de Honneth. Da leitura dos textos dos dois autores, conclui-se que ambos ajudaram a construir uma fundamentação filosófica para a necessidade da participação das pessoas com deficiência no processo legislativo e na formulação de políticas públicas para uma tutela mais efetiva de seus direitos.

$\mathrm{Na}$ quarta e última parte, já em considerações finais, conclui-se que (i) apesar da contribuição dos autores escolhidos para leitura para a fundamentação filosófica da necessidade de reconhecimento das pessoas com deficiência e sua participação no processo legislativo e na formulação de políticas públicas, ambos trazem fundamentos que correspondem apenas a etapas do percurso para a efetiva inclusão social das pessoas com deficiência; (ii) apesar dos avanços legislativos recentes, ainda há muito a se caminhar para que se concretizem os ideais de inclusão traçados no ordenamento brasileiro em vigor, notadamente através da educação de toda a sociedade para o conhecimento da normativa em vigor, de forma a torná-la operante.

\section{DA EXCLUSÃO A INCLUSÃO DAS PESSOAS COM DEFICIÊNCIA NA SOCIEDADE}

A Lei 13.146, de 06 de Julho de 2015, instituiu a Lei Brasileira de Inclusão, também chamada de Estatuto da Pessoa com Deficiência, alterando profundamente o regime das capacidades civis no ordenamento brasileiro, com impacto em vários ramos do Direito, notadamente no Direito Civil. 
O Estatuto da Pessoa com Deficiência foi aprovado como instrumento poderoso para a verdadeira inserção das pessoas com quaisquer deficiências, inclusive de natureza mental ou intelectual, na vida em sociedade, o que implica reconhecer a sua possibilidade de decisão e ação autônoma para decidir sobre aspectos existenciais de sua vida, por exemplo, casar e constituir família, e também patrimoniais, como empreender e contratar.

Embora os estudiosos e operadores do Direito inicialmente possam apresentar certa resistência à nova norma legal, por conta dos impactos e dificuldades trazidas, especialmente considerando que o legislador descuidou de considerar a estrutura do sistema jurídico já existente, descaracterizando institutos consagrados na tradição civil, como a capacidade civil e a curatela ${ }^{2}$, o Estatuto da Pessoa com Deficiência veio justamente para estabelecer novos paradigmas, e exigir a readequação do sistema.

A ciência jurídica sempre se ocupou mais do homem sem deficiências, e não tanto das pessoas que apresentam algum grau de dificuldade, congênita ou adquirida, na interação com o meio social, por muito tempo limitando-se a cuidar apenas dos seus aspectos patrimoniais, mas não do seu estatuto pessoal como um todo, de seus direitos existenciais, em prejuízo à sua autonomia e própria dignidade³ .

Buscando compreender este cenário, de um lado é espantoso que só em 2015 tenha sido aprovada uma lei com escopo amplo para promoção da inclusão em todos os aspectos da vida da pessoa com deficiência, e talvez a explicação seja porque justamente não se desse suficiente voz a estas pessoas, isto é, sua representação estivesse prejudicada. A mudança de paradigmas caminhou na esteira de movimentos de reconhecimento às pessoas com deficiência que já vinham ocorrendo em todo o mundo.

Para o melhor entendimento das mudanças havidas, é conveniente que se faça um resgate, ainda que sucinto, do tratamento do tema da deficiência pela sociedade, que repercutiu também nos ordenamentos jurídicos de vários países, entre eles o brasileiro.

Estudiosos do tema identificam, a partir do século XV, quatro fases distintas na relação entre as pessoas com deficiência e a sociedade, a saber, da exclusão, da segregação, da integração e da inclusão, didaticamente

\footnotetext{
${ }^{2}$ A título de ilustração das dificuldades decorrentes das alterações promovidas pelo EPD ao regime de capacidades, tomem-se os reflexos das mudanças feitas ao Código Civil no regime de invalidade dos atos jurídicos, e na possibilidade de produção de efeitos dos praticados por pessoas com deficiência intelectual mesmo quando em seu prejuízo. A doutrina ainda não alcançou solução pacífica sobre esta questão, tampouco sobre a aplicação dos prazos prescricionais para o exercício de pretensões nascidas da violação aos interesses das pessoas com deficiência. Com efeito, o artigo 198, I, do Código Civil, que prevê que não corre prescrição contra os incapazes de que trata o artigo $3^{\circ}$, operou como mecanismo de proteção às pessoas com deficiência de natureza intelectual até o advento do EPD. Entretanto, atualmente, discute-se o seu alcance para este grupo de pessoas, agora plenamente capazes. A respeito, ver SOUZA; SILVA, 2017.

${ }^{3}$ As expressões comumente usadas em passado recente para designar as pessoas com deficiência já eram bem indicativas do lugar que thes era reservado pela sociedade: deficiente, inválido, e, na lei civil até o advento do EPD, incapaz.
} 
representadas na ilustração a seguir ${ }^{4}$ :

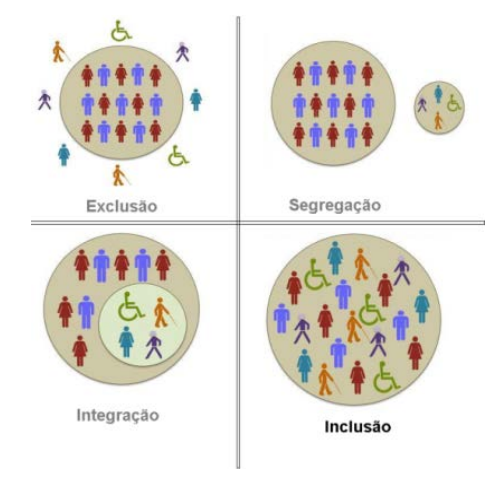

A primeira fase, identificada como da exclusão, é marcada pelo forte preconceito, com perseguição, punição, e até mesmo extermínio de pessoas com deficiência. Diante da falta de conhecimento científico sobre as doenças mentais e deficiências em geral, e em época em que a sociedade era extremamente religiosa, ainda não tendo chegado à chamada era da razão, explicava-se o transtorno mental por causas religiosas - o Papa Inocêncio VIII, baseando-se em texto retirado da Bíblia, escreveu uma bula papal em 1496, identificando as pessoas com deficiência como possuídas, com pacto com o demônio ${ }^{5}$ - , e assim muitas foram queimadas em praça pública, enforcadas, afogadas ou presas em nome de Deus. No século XV era comum o infanticídio, e crianças que nasciam com alguma deficiência eram sacrificadas ou escondidas. Uma representação literária que marca o tratamento desta época é a história do famoso personagem Quasímodo, o corcunda de Notre Dame, escrita pelo escritor francês Victor Hugo e publicada no livro intitulado Notre-Dame de Paris, em 1831. A Igreja ajudou a difundir a ideia de que as anormalidades de que padeciam as pessoas se deviam a causas sobrenaturais, associando a punição a pecados cometidos. As pessoas com deficiência simplesmente não se inseriam em sociedade, sequer iam à escola, e muito menos participavam da vida empresarial.

A segunda fase, que tem início entre o final do século XVIII e começo do século XIX, chamada de segregação, é marcada pelo isolamento social, pela caridade, e pelo assistencialismo. A Igreja passou a acolher as pessoas com deficiência, e foram constituídas escolas especiais em função das diferentes etiologias. Nesta época, duas importantes referências mundiais apareceram e influenciaram gerações: Phillipe Pinel ${ }^{6}$, pai da revolução

\footnotetext{
${ }^{4}$ Ilustração disponível em

https://www.google.com.br/search?q=exclus\%C3\%A3o+segrega\%C3\%A7\%C3\%A3o+integra\%C3\%A7\%C3\%A3o+inclus\%C3\% A3o\&rlz=1C1WPDB_enBR502BR504\&espv=2\&biw=1366\&bih=677\&source $=1 \mathrm{nms} \& \mathrm{tbm}=\mathrm{isch} \& \mathrm{sa}=\mathrm{X} \& v e d=0$ ahUKEwjo 90 2iYXMAhXE2SYKHUN3BQQQ_AUIBygC\&dpr=1. Acesso em 16-06-2018.

${ }^{5}$ FACIÓN, 2008, pág. 6.

${ }^{6}$ Philippe Pinel (Saint André, 20 de abril de 1745 - Paris, 25 de outubro de 1826) foi um médico francês, considerado por muitos o pai da psiquiatria. Notabilizou-se por ter considerado que os seres humanos que sofriam de perturbações mentais eram doentes e que ao contrário do que acontecia na época, deviam ser tratados como doentes e não de forma violenta. Foi o primeiro médico a tentar descrever e classificar algumas perturbações mentais.
} 
psiquiátrica e do atendimento mais humanizado; e Johann Heinrich Pestalozzi ${ }^{7}$, promovedor de escolas especiais, que criou as bases de um sistema educacional apoiado em dois subsistemas funcionando paralelamente e sem ligação: a educação especial e a educação regular. As pessoas com deficiências se inseriam, mas apenas em instituições especiais.

A terceira fase, chamada de integração, é marcada pela visão de que a pessoa com deficiência poderia conviver em sociedade, se beneficiar da sociabilidade com todos e não somente com certas pessoas e em ambientes específicos, desde que se adaptasse ao meio, se normalizasse através de treinamento. Ela tem predomínio entre as décadas de 50 a 80 do século XX, quando as pessoas com deficiência começaram a ter acesso a classes regulares, ao invés de instituições especiais, desde que se adaptassem sem causar qualquer transtorno ao contexto escolar. Apesar de mais integrativa, continuava impondo a seleção de quem vai à escola, aos ambientes de trabalho, de entretenimento, enfim, a todos os lugares. A escola, embora tenha passado a ser única, e contar com espaço integrado para momentos de sociabilidade, ainda destacava as pessoas com deficiência em classes separadas. O empenho inclusivo da sociedade ainda era baixo, limitando-se a mudanças físicas, como adaptações de calçadas e acessos a pavimentos, banheiros, para receber a pessoa com deficiência, que poderia conviver em sociedade, desde que ela tivesse condições de convivência.

A quarta fase, denominada de inclusão, em que atualmente se encontra a sociedade brasileira, aponta para outro caminho, de inserção concreta e muito mais abrangente. Em 1981, a Organização das Nações Unidas (ONU) instituiu o Ano Internacional das Pessoas Deficientes, fato que pode ser considerado o marco da sociedade inclusiva. Passou-se a dar atenção à necessidade de educar pessoas com deficiência no ensino regular, após a verificação das insatisfações existentes em relação às modalidades de atendimento em educação especial, que contribuíam para segregação e estigmatização dos educandos, e não davam resposta adequada a suas necessidades educacionais e sociais. $\mathrm{O}$ aluno com deficiência começou a frequentar classes regulares, pelo menos em meio turno, ainda que em alguns casos seja necessário o atendimento especializado para que sejam cumpridos os objetivos previstos no ordenamento em vigor.

O discurso da inclusão é muito mais potente que o da integração, pois pressupõe que todos são diferentes, que a sociedade é plural. A pessoa com deficiência neste contexto manifesta-se com relação a suas peculiaridades e necessidades, e a sociedade deve planejar e aplicar um sistema de apoio, através da prestação de serviços que visam qualidade de vida e participação, sem tentar normalizar ninguém, mas simplesmente reconhecendo as diferenças de todos.

\footnotetext{
${ }^{7}$ Johann Heinrich Pestalozzi, (Zurique, 12 de janeiro de 1746 - Brugg, 17 de fevereiro de 1827) foi um pedagogista suíço e educador pioneiro da reforma educacional. Começou suas atividades como educador após a invasão francesa da Suíça em 1798, quando acolheu crianças órfãs e sem abrigo que vagavam no Cantão de Unterwalden, reunindo-as em um convento abandonado.
} 
Passou-se, portanto, de um modelo médico no tratamento da deficiência, isto é, baseado sobretudo na perspectiva patológica da deficiência, para um modelo social, fundado na perspectiva de que a deficiência é um problema social, com causas de natureza diversas - não somente médicas, mas principalmente sociais, convocando instituições públicas e privadas a agir em prol da inclusão, através de ações multidisciplinares. O modelo social foca mais nas aptidões das pessoas com deficiência do que nos seus impedimentos, e exige, de toda a sociedade, contribuições que lhes permitam alcançar todas as potencialidades do seu desenvolvimento pessoal ${ }^{8}$.

\section{BREVE HISTÓRICO DA LEGISLAÇÃO BRASILEIRA RECENTE}

Sob a perspectiva de promoção de inclusão, o Brasil seguiu o movimento das legislações mundiais, e aqui uma das primeiras iniciativas foi a cota para contratações de trabalhadores com deficiência determinada no artigo 93 da Lei 8.213/1991, que trata da Previdência Social. Em Dezembro de 1993, a ONU aprovou o documento que deu forma às ideias lançadas no início dos anos 80, as Normas Uniformes sobre Igualdade de Oportunidades para as Pessoas Portadoras de Deficiência (AG.48/96, de 20-12-1993), solicitando aos Estados membros sua aplicação no desenvolvimento de programas nacionais em matéria de deficiência. Em 1994, na Conferência Mundial sobre Educação Especial, em Salamanca, na Espanha, a ONU aprovou a Declaração de Salamanca, assinada também pelo Brasil, pela qual os Estados se comprometeram a garantir que a educação de pessoas com necessidades especiais seja parte integrante do sistema educativo.

As aprovações da ONU foram determinantes para a organização e mobilização de políticas públicas, especialmente via PNUD99. As mudanças provocaram contínuos reflexos no Brasil. A Lei 10.098/2000 10 estabeleceu normas gerais e critérios básicos para a promoção da acessibilidade das pessoas portadoras de deficiência ou com mobilidade reduzida, mediante a supressão de barreiras e de obstáculos nas vias e espaços públicos, no mobiliário urbano, na construção e reforma de edifícios e nos meios de transporte e de comunicação.

Finalmente, em Março de 2007, a ONU aprovou a Convenção sobre os Direitos das Pessoas com Deficiência (também conhecida como Convenção de Nova York sobre Pessoas com Deficiência, neste trabalho adiante referida simplesmente como Convenção de Nova York, ou CDPD), o mais importante marco legislativo internacional da inclusão. A CPDP estabeleceu uma série de obrigações para os Estados signatários, entre os quais, reconhecer que as pessoas com deficiência gozam de capacidade legal em igualdade de condições com as demais pessoas em todos os aspectos da vida, devendo ser adotadas medidas relativas ao exercício da capacidade

\footnotetext{
${ }^{8}$ BARBOZA; ALMEIDA, 2017, págs. 13-18.

${ }^{9}$ PNUD (Programa das Nações Unidas para o Desenvolvimento) é a sigla referente à rede de desenvolvimento global das Nações Unidas que visa o desenvolvimento em várias áreas através de diferentes projetos.
} 
legal, que incluam salvaguardas apropriadas e efetivas para prevenir abusos, e que respeitem os direitos, vontades, e preferências da pessoa (art. 12).

Ao subscrever a Convenção de Nova York, os Estados membros também se comprometem a assegurar um sistema de educação inclusiva em todos os níveis de ensino. A CPDP determina expressamente que pessoas com deficiência não sejam excluídas do sistema educacional geral, e que tenham acesso ao ensino fundamental inclusivo, de qualidade e gratuito, em igualdade de condições com as demais pessoas na comunidade em que vivem (art. 24).

Logo após a aprovação da Convenção de Nova York, da qual o Brasil é signatário, e antes mesmo do seu processo formal de internalização ${ }^{11}$, o governo federal editou o Decreto 6.094, de 24-04-2007, que dispõe sobre a implementação do plano de metas Todos pela Educação, pela União, em colaboração com Municípios, Distrito Federal e Estados, e a participação das famílias e da comunidade, mediante programas e ações de assistência técnica e financeira, visando a mobilização social pela melhoria da qualidade da educação básica, e estabelecendo, dentre as diretrizes do plano, a garantia do acesso e permanência no ensino regular e o atendimento às necessidades educacionais especiais dos alunos, fortalecendo a inclusão educacional nas escolas públicas.

Em cumprimento pelo Estado Brasileiro das várias obrigações assumidas internacionalmente quando da assinatura da Convenção de Nova York, foi aprovado o Estatuto da Pessoa com Deficiência, com o fim de assegurar e promover, em condições de igualdade, o exercício dos direitos e das liberdades fundamentais pelas pessoas com deficiência, visando à sua inclusão social e cidadania (artigo $1^{\circ}$ ). O EPD buscou tratar de forma ampla de várias questões historicamente vistas como impeditivas do exercício da cidadania pelas pessoas com deficiência, dentre as quais, a título não exaustivo, discriminação, capacidade civil, e acessibilidade.

Conhecidos os antecedentes históricos do EPD, nota-se que referida lei ordinária foi a culminância de vários avanços sucessivos no reconhecimento das pessoas com deficiência, no seu empoderamento, em coerência com a forma com a qual a sociedade passou a enxergar as pessoas com deficiência e a si mesma nas décadas finais do século XX. O legislador buscou consolidar no Estatuto da Pessoa com Deficiência vários entendimentos que já vinham sendo prestigiados em normas esparsas, e instrumentalizar a CPDP, antes incorporada com força de norma constitucional, no plano infraconstitucional ${ }^{12}$.

Em que pese todas as mudanças legislativas ocorridas, e a migração do tratamento da questão da deficiência do modelo médico para o modelo social, ainda há muito a se avançar para o efetivo convívio das

\footnotetext{
${ }^{10}$ Regulamentada pelo Decreto 5.296/2004.

${ }^{11}$ A Convenção foi internalizada no direito brasileiro pela aprovação no Decreto Legislativo 186, de 09-07-2008 (em que o Congresso, seguindo o procedimento do $\$ 3^{\circ}$ do art. $5^{\circ}$ da Constituição, aprovou o texto com força de norma constitucional), e promulgação pelo Decreto 6.949, de 25-08-2009.

${ }^{12}$ BARBOZA; ALMEIDA JR, 2016. Pág. 207.
} 
pessoas com deficiência em condições de igualdade com todos os cidadãos. Em parte, porque o caráter promocional do Direito, inegável, produz efeito de apontar uma direção para a sociedade, um caminho escolhido conforme o contexto histórico, mas a cultura de valorização das pessoas com deficiência não se concretiza de um momento para outro.

\section{CONTRIBUIÇÃO DA FILOSOFIA DO DIREITO PARA O TEMA}

A modificação legislativa é um passo importante, e sinalizador de que outros já foram dados, mas não o único para a indicar o reconhecimento das pessoas com deficiência, que continuam, ainda, com pouca visibilidade na sociedade. E aqui a filosofia do Direito tem muito a contribuir. As indagações que coloca, as discussões que proporciona, sobre a (in)visibilidade das pessoas com deficiência permite colocar em debate e testar os mecanismos de reconhecimento e tutela de interesses, inclusive para apontar erros e acertos nas formulações de políticas públicas.

A filosofia do Direito apresenta questões de reconhecimento e representatividade, e permite uma melhor reflexão sobre como assegurar a efetiva participação das pessoas com deficiência na sociedade, para que os operadores busquem, através de normas de efeito prático, como o EPD e todas as modificações que proporcionou (por exemplo, na capacidade jurídica das pessoas com deficiência) atender da melhor forma, às demandas crescentes por maior autonomia e inclusão.

Especificamente no que diz respeito à ciência jurídica, cabe a questão de como assegurar que os interesses das pessoas com dificuldades de reconhecimento serão tutelados pelas normas jurídicas, de forma a garantir-lhes efetivo exercício de direitos. Para tentar responder a estas questões, propõe-se o exercício de imaginar a questão das pessoas com deficiência à luz dos pensamentos de dois autores de referência no campo filosófico-jurídico.

\section{John Rawls}

Uma teoria da justiça considerada entre as mais influentes do século XX é a de John Rawls, filósofo americano e professor na prestigiada Universidade de Harvard, falecido em $2002^{13}$, que aderiu expressamente à tradição do contrato social em seu $A$ Theory of Justice (1971). Segundo ele, os princípios de justiça são aqueles que pessoas livres e racionais preocupadas com seus próprios interesses futuros podem aceitar na posição inicial

\footnotetext{
${ }^{13}$ https://pt.wikipedia.org/wiki/John_Rawls
} 
de igualdade ${ }^{14}$.

Rawls retomou a figura do contrato social imaginando uma situação hipotética e histórica similar ao estado de natureza, a que chamou de posição original, na qual os indivíduos, concebidos como racionais e razoáveis, submetidos a um véu de ignorância (isto é, sem saber em que classe social estariam, qual o seu status, educação, concepções de bem, características psicológicas, etc) escolheriam princípios de justiça, assumindo que todos compartilhariam uma situação equitativa: seriam considerados livres e iguais.

Segundo Martha Nussbaum, filósofa filiada aos referenciais teóricos rawlsianos ${ }^{15}$, apesar de também usar a figura do contrato social ${ }^{16}$, Rawls diferia das visões que lhe antecederam, como as de Hobbes e Locke ${ }^{17}$, porque, primeiro, ele não presumiu que seres humanos tivessem direitos naturais no estado de natureza, e segundo, ele incluiu presunções morais antes evitadas - o véu da ignorância forneceu uma representação de imparcialidade moral, próxima à ideia Kantiana, de que ninguém pode ser usado como meio para os fins de outrem ${ }^{18}$. A ideia do autor não foi usada como recurso para fundamentar o processo histórico de formação do Estado (como na tradição do contratualismo clássico de Hobbes, Locke, e Rousseau), mas sim para fundamentar um processo de eleição dos princípios de justiça.

Para Nussbaum, Rawls deu nova roupagem à tradição do contrato social, desenvolvendo sobre do que trata a justiça quando pensamos na ideia de pessoas iguais, seus valores e capacidades. Sua contribuição apresentou importante resposta ao utilitarismo então dominante nas políticas públicas americanas, influenciadas pela visão econômica à época divulgada pela escola de Chicago $^{19}$, e contribuiu com uma forma mais rica e moralizada de pensar sobre elas.

Sem embargo, sua teoria foi insuficiente para lidar com alguns grandes problemas da justiça no mundo atual, dentre elas, as deficiências. A doutrina contratualista moderna de Rawls retificou razoavelmente algumas omissões pelos autores clássicos, como das mulheres, crianças e idosos da situação de barganha, mas não cuidou de tratar especificamente das pessoas com deficiências (físicas ou mentais), que continuaram sem participação no desenho dos princípios políticos básicos.

\footnotetext{
${ }^{14}$ RAWLS, 1997, pág. 128.

${ }^{15}$ Martha Nussbaum também é americana e, tendo passado pelas Universidades de Harvard e Brown, atualmente é titular da cátedra Ernst Freund Distinguished Service Professor of Law and Ethics na Universidade de Chicago. https://pt.wikipedia.org/wiki/Martha_Nussbaum.

${ }^{16}$ RAWLS, 1997, pág. 31.

${ }^{17}$ NUSSBAUM, 2007, págs. 9-12.

${ }^{18}$ Ibidem, pág. 12.

${ }^{19}$ A expressão escola de Chicago foi concebida na década de 1950 para identificar um grupo de professores e pesquisadores principalmente vinculados ao Departamento de Economia da Universidade de Chicago, mas também à Escola Superior de Administração e à Faculdade de Direito, que desenvolveu e promoveu o conceito do liberalismo econômico, e a valorização do livre mercado, baseando-se em teorias de formação de preços, contudo sem maiores preocupações com questões de justiça social, das quais Rawls se ocupou em sua obra, a partir da concepção da justiça como equidade.
} 
Em alinhamento com esta omissão jusfilosófica dominante na segunda metade do século XX, na maior parte das sociedades, até recentemente, estas pessoas eram segregadas da vida em sociedade e estigmatizadas pela maior parte da população.

A omissão na situação da escolha básica é um defeito do ponto de vista da justiça, como a própria Nussbaum, ainda que defensora da obra de Rawls, aponta. Os arranjos práticos que não incluem as necessidades de certas pessoas no grupo original contratante faz com que elas não tenham liberdade de redesenhar os princípios de justiça à luz de suas próprias consciências sobre estas questões.

Deve-se lembrar que as teorias do contrato social combinam duas questões primordiais: primeiro, por quem os princípios básicos da sociedade são desenhados e segundo, para quem eles são desenhados ${ }^{20}$. Para os aderentes ao contratualismo, o fato de as pessoas com deficiências não serem incluídas entre os atores políticos significa que elas não serão consideradas na elaboração dos princípios, salvo de maneira derivada ou em estágio posterior.

Nussbaum pondera que Rawls é sutil neste ponto, porque ele distingue as partes na posição original daquelas que vão, como cidadãos em uma sociedade, desenhar os princípios - os cidadãos têm as limitações informacionais através do uso do véu da ignorância -, mas a autora pondera que nas questões relacionadas a deficiências esta diferença não é significante.

Para Nussbaum, as questões 'por quem' e 'para quem' não precisam estar ligadas da maneira que são. Pode haver uma teoria que assegure que quaisquer pessoas (e até mesmo outros seres vivos que não os humanos ${ }^{21}$ ) sejam primariamente sujeitos de justiça, mesmo sem capacidade de participar dos procedimentos através dos quais os princípios políticos são escolhidos. A capacidade de realizar o contrato que busca vantagens mútuas na sociedade resultante não é condição para que um ser tenha dignidade e mereça ser tratado com respeito em relação de igualdade com outros.

Em coerência com a mudança de entendimento sobre o tema, bem refletida na obra de pensadores mais atuais, como Nussbaum, a questão da justiça para pessoas com deficiências está atualmente na agenda de qualquer sociedade comprometida com direitos fundamentais.

Mas a omissão de sua participação nas situações de escolhas políticas básicas ainda parece problemática, dada a evidente capacidade de escolha de muitos, senão da maioria ${ }^{22}$. Com efeito, mesmo que os interesses das

\footnotetext{
${ }^{20}$ NUSSBAUM, 2007, pág. 16.

${ }^{21} \mathrm{O}$ reconhecimento de outros seres vivos que não o ser humano como sujeito de direito é ainda incipiente, mas o movimento para o seu reconhecimento vem ganhando força, e gerando reflexos nos ordenamentos jurídicos de diversos países. Cite-se, a titulo de exemplo, o habeas corpus dado a uma chimpanzé na Argentina em novembro de 2016 (Processo P-72.254/15, da Província de Mendoza), e ainda, a Lei portuguesa no 08/2017, que, alterando o Código Civil português, reconhece os animais como seres vivos dotados de sensibilidade e objeto de proteção jurídica.

${ }^{22}$ NUSSBAUM, 1997, pág. 18.
} 
pessoas com deficiência possam ser levados em conta de forma derivada ou em estágio posterior, questiona-se se este adiamento é necessário e se não afeta um tratamento verdadeiramente igual destas pessoas. A inclusão total de pessoas com deficiências (sejam elas de ordem física, sensorial, mental ou intelectual, independentemente das importantes distinções nos desafios enfrentados por cada um dos integrantes deste vasto grupo ${ }^{23}$ ) levanta questões que vão, portanto, ao coração da teoria contratual de justiça e cooperação social.

Os movimentos sociais e de elaboração normativa são ilustrativos. Se, de um lado, o Estatuto da Pessoa com Deficiência foi a culminância de uma série de ações e esforços legislativos com o escopo de tutelar de maneira mais completa e respeitosa os interesses das pessoas com deficiência, por outro lado, talvez a explicação para a demora para a edição de uma norma específica com tamanha abrangência e alcance seja justamente porque não se desse suficiente voz às pessoas diretamente afetadas pela norma.

Com efeito, apesar de o Brasil ter aderido à Convenção de Nova York em 2009, a efetiva mudança legislativa para instrumentalização dos seus preceitos na ordem interna ocorreu somente bem mais tarde ${ }^{24}$, com participação ativa de congressistas que vivem em sua experiência pessoal a realidade da pessoa com deficiência ${ }^{25}$, ou o convívio com elas ${ }^{26}$, permitindo que suas questões ganhassem projeção no debate legislativo.

Tal constatação evidencia e reforça a crítica feita por Nussbaum à teoria contratualista de Rawls, no sentido de que não é suficiente que as normas seja pensadas e produzidas para as pessoas com deficiência, elas devem ser também formuladas por elas. Elas devem ter sua representatividade assegurada para que possam criar normas que efetivamente tutelem os seus interesses, contribuam para a proteção dos seus direitos.

\footnotetext{
${ }^{23}$ Art. 20 EPD: "Considera-se pessoa com deficiência aquela que tem impedimento de longo prazo de natureza física, mental, intelectual ou sensorial, o qual, em interação com uma ou mais barreiras, pode obstruir sua participação plena e efetiva na sociedade em igualdade de condições com as demais pessoas."

${ }^{24}$ A título comparativo, veja-se, por exemplo, a diferença na demora no processo legislativo em relação a dois temas distintos, ambos sobre os quais o Brsail assumiu compromissos internacionais: 1) Comércio internacional: Em abril de 1994, o Acordo Constitutivo da Organização Mundial do Comércio ("Acordo da OMC") foi assinado em Marraqueche, tendo o Estado Brasileiro também sido signatário. O Acordo da OMC foi incorporado à ordem interna brasileira no mesmo ano (através do Decreto Legislativo no 30, de 15-12-1994 e do Decreto no 1.355, de 30-12-1994), e entrou em vigor em Janeiro de 1995. Entre os anexos da OMC, consta o Acordo sobre Aspectos dos Direitos de Propriedade Intelectual (TRIPS), que exigiu adaptações na legislação interna brasileira sobre propriedade industrial, tendo a Lei no 9.279, sido sancionada, após o trâmite no Congresso Nacional, em 14-05-1996, portanto um pouco mais que dois anos após a assinatura do Tratado da OMC; 2) Inclusão da Pessoa com deficiência: a Convenção sobre os Direitos das Pessoas com Deficiência foi assinada em Nova York em Março de 2007, também subscrita pelo Estado Brasileiro. Após internalização do Tratado através da aprovação do Decreto Legislativo 186, de 09-07-2008, e promulgação pelo Decreto 6.949, de 25-08-2009, a legislação brasileira só foi alterada, para enfim dar cumprimento aos compromissos assumidos com relação às pessoas com deficiência, através da Lei no 13.146, de 06-07-2015 (o EPD). O intervalo entre a assinatura do tratado internacional e a aprovação da lei interna foi de mais de 8 anos, bem maior do que no primeiro exemplo, relativo ao tema do comércio internacional.

${ }^{25}$ Como os deputados federais Mara Gabrilli, de São Paulo, tetraplégica após acidente de carro; Rosinha da Adefal, de Alagoas, sem mobilidade das duas pernas desde os dois anos de idade, por conta de poliomielite; e Walter Tosta, do Rio de Janeiro, paraplégico aos 15 anos, após ser atingido por bala perdida, os três casos evidenciando tristemente problemas da sociedade brasileira, a irascibilidade no trânsito, o descaso com a saúde pública no cumprimento de políticas de prevenção de doenças, e a violência urbana.
} 
Mas não é só. Diante das considerações acima, do ponto de vista da teoria contratualista rawlsiana, ainda que revisitada e mais oxigenada pelas ponderações de Nussbaum, pode parecer que a mera produção legislativa relacionada às pessoas com deficiência, desde que seja realizada com sua participação, seja suficiente para o seu pleno reconhecimento e tutela de interesses.

É preciso lembrar, contudo, que a teoria de Rawls é contra fática, se baseia em pressupostos, e não em fatos reais, e assume uma capa de neutralidade que presume que os mesmos princípios devem ser aplicados a todos, não ressalvando que a tutela das pessoas com deficiência, a fim de que possa ser assegurada sua igualdade de participação na sociedade, deva ser diferenciada em relação aos demais cidadãos.

Dentro da ótica rawlsiana, por exemplo, a mera inserção estrutural de um texto legislativo prevendo igualdade de direitos de todos, inclusive das pessoas com deficiência, parece suficiente, não permitindo seu pensamento filosófico estender muito a reflexão sobre quais mecanismos o Direito pode oferecer para acesso efetivo aos direitos pelas pessoas com deficiência. Quais compensações e, na expressão da Convenção de Nova York, mecanismos de salvaguarda, podem ser, eventualmente, especificamente necessários ao pleno exercício dos direitos existenciais e patrimoniais pelas pessoas com deficiência.

A leitura de Rawls é, pois, uma etapa fundamental para reflexão crítica sobre o reconhecimento, mas insuficiente. Ela indica uma parte do caminho, mas não todo o percurso para o efetivo reconhecimento das pessoas com deficiência tanto no momento da produção quanto no de interpretação e aplicação das normas legais.

\section{Axel Honneth}

Axel Honneth é um filósofo e sociólogo alemão, professor na Universidade Johann Wolfgang Goethe, de Frankfurt ${ }^{27}$, instituição na qual surgiu a chamada Escola de Frankfurt ${ }^{28}$.

Em seu livro Luta por Reconhecimento: a gramática moral dos conflitos sociais (1996), influenciado, entre outros referenciais teóricos, por escritos do jovem Hegel sobre a intersubjetividade (que revela como cada um se constitui a partir do outro), Honneth ponderou que os processos de mudança social estão ligados à relação de reconhecimento recíproco, que produz reflexo também na normatividade. Honneth apresentou a ideia de que expectativas normativas morais conformam a autopercepção dos indivíduos, e, na medida em que estas

\footnotetext{
${ }^{26}$ Como os senadores eleitos pelo Rio de Janeiro, Romário e Lindbergh Farias, cujas filhas têm síndrome de Down.

${ }^{27}$ https://pt.wikipedia.org/wiki/Axel_Honneth

${ }^{28}$ A expressão escola de Frankfurt designa uma vertente de teóricos sociais e filósofos associados ao Instituto para Pesquisa Social da Universidade de Frankfurt, na Alemanha, formada inicialmente por cientistas sociais críticos tanto do capitalismo e do socialismo da extinta União Soviética, com textos que buscavam um caminho alternativo para o desenvolvimento social.
} 
expectativas são desrespeitadas, tornam-se combustível de conflitos pelo reconhecimento de suas qualidades.

Um dos pontos de partida das ponderações de Honneth é, como mencionado, a teoria de Hegel ${ }^{29}$, segundo a qual a reprodução da vida social se efetua sob um imperativo de um reconhecimento recíproco, que ocorre através de lutas moralmente motivadas por grupos sociais, a fim de estabelecer o reconhecimento recíproco dentro da cultura, das instituições, e também no seio das normas jurídicas.

Mas Hegel, segundo Honneth, não conseguiu definir quais seriam as formas de desrespeito que consistem na experiência dos atores sociais como forma de reconhecimento denegado. Então, ele formula a pergunta sobre quais seriam as experiências de desrespeito capazes de denegar o reconhecimento, e procura respondê-la.

Honneth entende que seriam três os modos de reconhecimento: o amor (a dedicação emotiva, capaz de gerar a autoconfiança individual), o Direito (o respeito cognitivo, capaz de gerar o sentimento de autorrespeito), e a solidariedade (a estima social, responsável pela autoestima individual). A cada uma destas formas de reconhecimento nas relações sociais, corresponderia, na teoria do Honneth, uma forma especifica de não reconhecimento. Tanto as experiências de reconhecimento quanto as de falta de reconhecimento podem abranger diferentes graus.

O desrespeito ao indivíduo nas diferentes instâncias de reconhecimento importa em um comportamento lesivo pelo qual cada pessoa é ferida na própria possibilidade de se compreender de maneira positiva.

Com relação à esfera do amor, o não reconhecimento se daria através de experiências de maus tratos e degradação física, que atingem a capacidade de uma pessoa dispor livremente do seu corpo, como a agressão física, a violação e a tortura. Com relação à instância do Direito, o não reconhecimento se dá pela privação de direitos, a negação de pretensões jurídicas, lesando a expectativa de reconhecimento do sujeito como capaz de formar juízo moral, e provocando a perda do autorrespeito. Com relação à esfera da solidariedade, a perda de autoestima refere-se ao valor social de indivíduos ou grupos. O não reconhecimento resulta na visão de que a condução da vida do sujeito não teria significado positivo no interior de uma coletividade.

Ao defender a ideia central do seu trabalho, de que o indivíduo precisa de reconhecimento, Honneth não está preocupado em dizer se o Direito confere acesso a direitos, mas trata o Direito enquanto instância de reconhecimento, e da importância do que ele produz sobre o indivíduo - em outras palavras, uma parte da existência está no reconhecimento pelo Direito, que é a introjeção dos valores da sociedade: o que o Direito diz de cada pessoa é o que ela vale para a sociedade.

${ }^{29}$ HONNETH, 2003, pág. 29. 
Mesmo fortemente embasado em referenciais kantianos, o que the aproximaria do transcendentalismo/universalismo rawlsiano, Honneth encarna o sujeito, isto é, aproxima-o de uma perspectiva mais concreta e não meramente transcendental, ao dizer que o Direito dá acesso a um direito, mas também dá acesso a um projeto de formação do sujeito e suas subjetividades. Portanto, para Honneth, o Direito tem um papel socializador fundamental: junto às outras esferas de reconhecimento, o Direito também contribui para produzir o indivíduo.

Conjugando as reflexões trazidas por Honneth em sua teoria da luta pelo reconhecimento à evolução da normativa acerca das pessoas com deficiência no ordenamento brasileiro, conclui-se que apenas com a oportunidade de reconhecimento das pessoas com deficiência na esfera do Direito que elas terão, não apenas efetivo acesso a direitos, mas, antes disto, também acesso a um projeto próprio de formação como sujeito de Direitos. Em outras palavras, o Direito, enquanto instância de reconhecimento, confere às pessoas com deficiência o auto entendimento de que são e devem estar inseridas na sociedade, e merecedoras de tutela como quaisquer outras.

Esta concepção do Direito como formador de sujeitos e subjetividades está em linha com o pensamento atual de inclusão das pessoas com deficiência. Não por outra razão hoje prepondera, ao menos na quase totalidade dos Estados Democráticos, o entendimento de que a sociedade é plural, e deve ser inclusiva, respeitando as diferenças e valorizando-as.

Honneth encara o reconhecimento como categoria moral fundamental, e evidencia que o papel do Direito é mais amplo do que a mera concessão ou não de direitos. Segundo ele, para que haja evolução moral na sociedade, deve haver reconhecimento recíproco. A sociedade não é um contrato entre indivíduos solipsistas, a inscrição social é intersubjetiva. Para o autor, o processo de individuação é posterior à experiência social - é a partir da dinâmica social que o sujeito se individua.

Neste sentido, todas as mudanças ocorridas na legislação brasileira com relação às pessoas com deficiência, não apenas lhes asseguram melhor acesso aos seus direitos, mas contribuem fundamentalmente para sua formação subjetiva, para o seu reconhecimento como merecedores de tutela, e para o melhor entendimento, não só pelas pessoas com deficiência, mas por todas as pessoas que convivem em sociedade, de que a sociedade é plural e que as pessoas devem reconhecer e respeitar as diferenças. Embora as reflexões sobre o reconhecimento tenham ganhado força nas agendas legislativas internacionais, Honneth não indicou como o acesso ao reconhecimento das pessoas com deficiência é feito, tampouco se ocupou de refletir sobre os empecilhos existentes. Seu trabalho oferece contribuição importante, portanto, mas ainda insuficiente para a plena inclusão das pessoas com deficiência na vida em sociedade. 


\section{CONSIDERAÇÕES FINAIS}

O conhecimento de diferentes teorias filosóficas, como as duas aqui sucintamente apresentadas, permite ponderar com mais profundidade sobre o impacto de qualquer política pública, notadamente qualquer mudança legislativa, entre elas, todas as relacionadas ao reconhecimento e ao acesso a direitos.

Conclui-se, da análise dos textos abordados neste trabalho, que John Rawls, com suas reflexões sobre a posição original na formação do contrato social como caminho para fundamentar um processo de escolha de princípios de uma justiça, deixou de indicar a importância da participação das pessoas com deficiência no processo legislativo, contudo, com as bases que colocou sobre a concepção de justiça como equidade, acabou permitindo esta reflexão por pensadores que posteriormente fizeram a releitura de seus textos, como Martha Nussbaum. Não obstante esta contribuição, que constituiu etapa fundamental para reflexão crítica sobre a representatividade, ela ainda é insuficiente, indicando apenas parte do caminho para a inclusão das pessoas com deficiência.

Axel Honneth, com seus estudos sobre as diferentes esferas de reconhecimento, também contribuiu para a melhor teorização da importância da instância do Direito como produto e produtor dos sujeitos, permitindo uma reflexão mais rica sobre o papel da norma jurídica no reconhecimento das pessoas com deficiência, e sua efetiva inclusão na vida em sociedade. Todavia, sua contribuição é, igualmente, apenas uma etapa em um longo percurso para o efetivo reconhecimento das pessoas com deficiência - não apenas no momento da produção das normas legais, mas principalmente de sua interpretação e aplicação.

Condição fundamental para concretização dos ideais de inclusão traçados no ordenamento brasileiro em vigor, de acordo com as mudanças legislativas feitas nos últimos anos, é garantir o acesso, pelas pessoas com deficiência, às normas de reconhecimento, isto é, seu conhecimento da legislação em vigor, o que passa por uma educação para a inclusão, não apenas dos próprios sujeitos cujos interesses são tutelados pela legislação, mas de toda a sociedade.

Os atores sociais que pretendam contribuir (presumindo-se sua genuína boa-fé) uma sociedade que se pretenda mais inclusiva e solidária, além das boas intenções, devem estar atentos às particularidades das representações que propõem. Por paradoxal que pareça, atores sociais plenos de boas intenções podem não atingir os resultados almejados através de suas ações. Por exemplo, legisladores bem intencionados podem elaborar leis ruins para aquelas pessoas cujos interesses pretendem tutelar. Porque o reconhecimento pode não existir de verdade, ou pior, existir atrelado a uma mensagem negativa, ou a prescrições contraproducentes. Da mesma maneira, a academia deve ter cuidado na produção de textos críticos, seja em relação à normativa existente, seja em relação às ações tomadas na concretização de políticas públicas, para que os avanços conquistados em 
termos normativos não sejam esvaziados na aplicação dos dispositivos legais.

Com efeito, embora se reconheça a importância dos textos legislativos em vigor no Brasil, que concretamente jogaram luz às causas de inclusão, devido à influência que possuem na vida em sociedade, deve-se reconhecer que, para uma sociedade verdadeiramente mais inclusiva, é sempre necessário questionar como a normativa está sendo colocada em prática.

A solidariedade, princípio fundante do nosso ordenamento jurídico, consubstanciado expressamente no artigo $3^{\circ}$, I, da Constituição brasileira, deve ser promovida concretamente, e pessoas que não dependem do reconhecimento (porque já o têm em todas as esferas de suas vidas, no amor, no reconhecimento dos direitos, e na solidariedade social, ou simplesmente, já o têm em maior grau em comparação a outras) podem e devem se engajar na luta pelo reconhecimento daqueles que não têm, contribuindo, da melhor maneira possível, para o protagonismo dos que sofrem com o não reconhecimento.

Neste contexto, o estudo de diferentes teorias filosóficas que afetam a tutela de interesses e a normatividade é fundamental para orientar o pensamento crítico e ação responsável de qualquer ator social, com impacto na conduta e na tutela de interesses e direitos, sobretudo os existenciais.

Superada a etapa de mudança legislativa, é importante agora que na interpretação e aplicação da Convenção e do Estatuto da Pessoa com Deficiência, estas reflexões sejam também lembradas. Isto porque, apesar dos avanços obtidos em vários aspectos, os legisladores, ainda que bem intencionados, não garantem que os operadores de Direito irão aplicar a normativa existente de forma efetivamente protetiva dos destinatários da previsão legal, e não desarrazoadamente tolher-lhes a autonomia e iniciativa.

A desconsideração desta importante premissa parece se dever à excessiva generalização da norma legal. Se por um lado, pelo histórico das deficiências a bandeira da inclusão é comum a todos os grupos de pessoas com deficiência, as formas de inclusão, os mecanismos de que devem se valer cada pessoa para efetivamente serem incluídos na sociedade, não são.

Em outras palavras, todos os grupos merecem ter acesso à inclusão, mas cada grupo deve usar o ferramental adequado, de acordo com as peculiaridades de suas próprias necessidades especiais, para se fazer incluir. 


\title{
NORMS OF RECOGNITION OF PERSONS WITH DISABILITIES: REFLECTIONS BASED ON RAWLS AND HONNETH
}

\begin{abstract}
Having as factual support the legislative change that occurred in the Brazilian legal system in relation to persons with disabilities, through the approval of Law 13.146/2015, this paper aims to highlight the importance of the study of philosophical theories that deal with recognition for the formation of critical thinking in the creation and interpretation of inclusion legal rules. It was used the descriptive method for the analysis of the texts of John Rawls and Axel Honneth, taking some of the theoretical references formulated by the authors, notably on the subject of participation in the social contract (in Rawls' work) and on the struggle for recognition (in Honneth's work). From the reading of the two authors, it has been concluded that both of them helped to build a philosofical justification for the need of participation of persons with disabilities in the legislative process and in the formulation of public policies for a more effective protection of their rights. Despite this result, and the legislative advances in recent years, the author considers there is still much progress to be made in order to make the ideals of inclusion outlined in Brazilian law concrete.
\end{abstract}

Keywords: Recognition; Inclusion; Person With Disability Act; John Rawls; Axel Honneth.

\section{REFERÊNCIAS BIBLIOGRÁFICAS}

BARBOZA, Heloisa Helena Gomes; ALMEIDA JR, Vitor de Azevedo Almeida. A (in)capacidade da pessoa com deficiência mental ou intelectual. In EHRHARDT JR, Marcos (coord.) Impactos do novo CPC e do Estatuto da Pessoa com Deficiência no Direito Civil Brasileiro. Belo Horizonte: Forum, 2016. Pág. 205-227.

BARBOZA, Heloisa Helena Gomes; ALMEIDA JR, Vitor de Azevedo. Reconhecimento, inclusão e autonomia da pessoa com deficiência: novos rumos na proteção dos vulneráveis. In BARBOZA, Heloisa Helena Gomes; MENDONÇA, Bruna Lima de; ALMEIDA JUNIOR, Vitor de Azevedo (coord). O código civil e o estatuto da pessoa com deficiência. Rio de Janeiro: Processo, 2017. Págs. 1-30.

FACIÓN, José Raimundo. Inclusão escolar e suas implicações. 2ª ed. Curitiba: IBPEX, 2008.

HONNETH, Axel. Luta por reconhecimento: a gramática moral dos conflitos sociais. 1a edição. São Paulo: Editora 34 Ltda., 2003.

NUSSBAUM, Martha Craven. Frontiers of Justice: disability, nationality, species membership. 1st edition. Massachusetts: First Harvard University Press paperback edition, 2007.

RAWLS, John. Uma teoria da justiça. 1ª edição. São Paulo: Martins Fontes, 1997.

SOUZA, Eduardo Nunes de; SILVA, Rodrigo da Guia. Influências da incapacidade civil e do discernimento reduzido em matéria de prescrição e decadência. Revista Pensar, Fortaleza, v. 22, n. 2, págs. 469-499, maio/ago. 2017. 
Quaestio Iuris

Trabalho enviado em 11 de março de 2018.

Aceito em 23 de junho de 2018. vol. 11, n. 03, Rio de Janeiro, 2018. pp. 1840-1857 DOI: $10.12957 /$ rqi.2018.33135 